\title{
Nar (Punica Granatum L.) Bitkisinin Doğal Mordanlarla Boyama ve Haslık Değerleri
}

\author{
Doç. Dr. Fatma Nur Başaran ${ }^{1^{*}}$ \\ Şengül Aydın²
}

Geliș tarihi: 30.09 .2019

Kabul tarihi: 07.11.2019

\section{Atıf bilgisi:}

IBAD Sosyal Bilimler Dergisi

Sayı: $5 \quad$ Sayfa: $397-406$

Yıl: 2019 Dönem: Güz

This article was checked by intihal.net. Similarity Index 18\%

\footnotetext{
${ }^{1}$ AHBV Üniversitesi, Sanat ve Tasarım Fakültesi, Tekstil Tasarımı Bölümü, Türkiye, fatma.basaran@hbv.edu.tr ORCID ID 0000-0002-6024-1709

${ }^{2}$ Gazi Üniversitesi, Güzel Sanatlar Enstitüsü, Tekstil Tasarımı Ana Bilim Dalı, Yüksek Lisans Öğrencisi, Türkiye, fatma.basaran@hbv.edu.tr
}

ORCID ID 0000-0002-6024-1709

\section{* Sorumlu yazar}

\begin{abstract}
ÖZ
Doğa, insanlara tüm görkemi ve zenginliği ile görseller sunarak "renklilik" kavramını oluşturmada yardımcı olduğu gibi, renk veren kaynakları ile malzeme de sağlamıştır. Zamanla boyama yöntemlerinin geliştirilmesi, yüksek teknolojilerle iplik ve kumaşlar üzerine uygulanmasına rağmen, doğal kaynaklar ve özellikle bitkisel boyalar tekstillerin renklendirilmesinde her zaman özel bir yere sahip olmuştur. Bitkisel boyalar; renk veren bitkilerin yaprak, çiçek, kozalak, gövde kabukları, kök, sürgün vb. kısımlarından elde edilmektedir. Bitkisel boyalarla doğrudan boyama yapılabildiği gibi, aynı zamanda yardımcı maddelere de ihtiyaç duyulmaktadır. Mordan adı verilen bu maddeler, boyarmaddenin liflere daha iyi tutunmasını, iyi bir renk haslığı ile aynı bitkiden farklı renk tonları elde edilmesini sağlamaktadır. Doğal boya üretiminde bitkisel atıklar, geri dönüşüm olarak değerlendirilmesi ve temiz bir boyama teknolojisi ile çevreyle uyumu açısından ilgi çekmekte ve doğal boyaların önemini artırmaktadır. $\mathrm{Bu}$ aşamada bitkisel boyarmaddelerin yanı sıra doğal mordanlar da önem kazanmaktadır. Dolayısıyla bu araştırmada, boyarmadde olarak nar bitkisinin çeşitli kısımları, mordan olarak da labada kökü ve kül suyu kullanılmıştır. Çalışmanın amacı, nar bitkisinin, kabuk, çiçek ve yapraklarından elde edilen boyarmadde ve doğal mordanlarla boyanan yün ve pamuk ipliklerinin renk özelliklerini incelemek ve haslık düzeylerini belirlemektir. Yün ve pamuk ipliklerinin boyanmasında mordansız ve birlikte mordanlama yöntemleri kullanılmış; yıkama ve sürtünme haslık testleri yapılmıştır. Araştırma sonucunda nar kabuğu ve nar yaprağı ile yakın renk tonlarının elde edildiği, nar çiçeği ile farklı renklere ulaşıldığı; kül suyu mordanının haslık test sonuçlarının daha yüksek olduğu tespit edilmiştir.
\end{abstract}

Anahtar Kelimeler: Bitkisel boyarmadde, Haslık, Mordan, Nar, Organik. 


\title{
Coloring and Fastness Values of Pomegranate (Punica Granatum L.) Plant with Natural Mordants
}

\author{
Doç. Dr. Fatma Nur Başaran ${ }^{1 *}$ \\ Şengül Aydın ${ }^{2}$
}

First received: 30.09 .2019

Accepted: 07.11.2019

\section{Citation:}

IBAD Journal of Social Sciences

Issue: $5 \quad$ Pages: 397-406

Year: $2019 \quad$ Session: Fall

This article was checked by intihal.net. Similarity Index 18\%

${ }^{1}$ AHBV University, Faculty of Arts and Design, Department of Textile Design, Turkey,

fatma.basaran@hbv.edu.tr

ORCID ID 0000-0002-6024-1709

${ }^{2}$ Gazi University, Institute of Fine Arts, Textile Design Department, Graduate Student, Turkey, fatma.basaran@hbv.edu.tr

ORCID ID 0000-0002-6024-1709

\section{* Corresponding Author}

\begin{abstract}
Nature provides materials with coloring sources as well as helping to create the concept of "colorfulness" by presenting images with all of its glory and richness. Although the dyeing methods are improved and applied on threads and fabrics with advanced technologies, using natural sources and natural dyes in the coloring of textiles always had a special place. Natural dyes are obtained from the leaves, flowers, cones, tree barks, roots, suckers, etc. of colorant plants. Although dyeing can be performed with natural dyes, auxiliary products are needed at the same time. These products called mordant provide the dyestuff to fasten on the fibers and to obtain a good color fastness and different color tones from the same plant. In natural dye production, natural wastes draw attention in terms of recycling and its environmental compliance with a clean dyeing technology and increase the importance of natural dyes. At this stage, natural mordants also become important in addition to the natural dyestuffs. Thus, in this study, various parts of the pomegranate plant and dock root and lye natural mordants were used. The aim of the study is to examine the color features of wool and cotton threads that were dyed with natural mordants and the dyestuff obtained from the pell, flower, and leaves of pomegranate plant and to determine the fastness levels. Non-mordanted and simultaneous mordanting methods were used in the dyeing of wool and cotton threads, fastness tests of washing and rubbing were conducted. As a result of the research, pomegranate peel and pomegranate leaf with close color tones are obtained, pomegranate flower is reached with different colors; fastness test results of ash water mordant were found to be higher.
\end{abstract}

Keywords: Natural dyestuff, Fastness, Mordant, Pomegranate, Organic. 


\section{GİRIŞ}

Eski çağlardan beri insanlar, tabiatta gördükleri renkler ve renklerin oluşturduğu kompozisyonlar karşısında hayranlık duyarak doğadan faydalanmış ve birçok boyarmadde elde etmiştir (Öztürk, 1999, s. 6). $\mathrm{Bu}$ nedenle toplumların ilk süsleme elemanlarını, çiçek, yaprak ve çeşitli doğal renkli taşlar oluşturmaktadır (Durul, 1985, s. 44). İnsanın tarihsel gelişim sürecinde hayvansal, bitkisel ve mineral kökenli doğal boyarmaddelerden yararlandığı bilinmektedir. Bunların içinde doğada en fazla bulunan, renk seçeneği en çok ve kullanım açısından en kolay olanı, bitkilerden elde edilen doğal boyarmaddeler olmuştur (Gönüz, Aksoy ve Karabacak, 2006, s. 56). Boyamacılıkta önceleri bitkilerin çiçek, yaprak, meyve, gövde ve köklerinden (Harmancioğlu, 1955, s. 1) yararlanan insanlar, zamanla doğal boyarmaddeleri ve boyama yöntemlerini geliştirmişlerdir. Etikan ve Ölmez (2014, s. 56) bitkisel boyacılığın Türk kültüründe köklü bir geleneğe sahip olduğunu, Pazırık kurganlarından çıkan keçe, kumaş, halı ve kilimlerin renklendirilmesinde doğal boyarmaddelerin kullanıldığının belirlenmesi ile ortaya koyulduğunu ifade etmektedir. 19. Yüzyılın ortasına kadar boya veren bitkiler ve hayvanlar tekstillerin ana renk kaynakları olmuştur (Alkan, Torgan ve Karadağ, 2017, s. 1).

İklim çeşitlerine göre bazı bitkiler kendiliğinden yetişirken, bazı bitkilerin kültürü yapılmaktadır. Boya veren önemli bitkiler; asma (Vitis vinifera L.), aspir (Carthamus tinctorius L.), bodur mürver (Sambucus nigra L.), ceviz (Juglans regia L.), kökboya (Rubia tinctorium L.), nar (Punica granatum L.), sergil (Plumbago europeae L.), soğan (Allium cepa L.) vb.'dir (Şanlı ve Arlı, 2007, s. 57). Doğal boyamacılıkta bitkilerin toplanma zamanları da çok önemlidir. Boyarmadde olarak kullanılan bitkilerin çiçek ve tohumları olgunlaştıktan sonra, yaprakları bitki çiçek açtığı zaman, kabukları ise bitki yapraklarını döktükten sonra, bitkiye zarar vermeden toplanır ya da kesilmiş ağaç kabuklarından ve ağaç dallarından yararlanılır (T.C. Sanayi ve Ticaret Bakanlığı, 1991, s. 14).

Doğal boyaların, üretim ve tüketimi çevreye zarar vermemektedir ve uğraş alanı biraz fazla olsa da kimyasal yollarla elde edilen sentetik boyalara göre üretimi oldukça ekonomiktir (Soysaldı, 2000, s. 61). Pek çoğu, boya bitkileri yönünden zengin olan Anadolu'nun, hemen her bölgesinde kendiliğinden yetişmekte veya tarımı yapılmaktadır. Bu bitkilerden elde edilen boyarmaddeler çeşitli alanlarda kullanılmaktadır. Boyama özelliğine sahip bitkilerin yapısında etkin kimyasal maddeler bulunmasından dolayı, bitkiye herhangi bir kimyasal işlem uygulanmadan boyarmadde elde edilmesinin yanı sıra kimyasal işlemler uygulanarak da elde edilebilmektedir.

Boya bitkilerinden biri olan nar (Punica Granatum); ağaç veya çalı görünümünde, yaprakları şerit halinde, mayıs ve haziran aylarında al kırmızımsı çiçek açan ve kış aylarında yaprağını döken, 5-6 metre boyunda seyrek dallı, geniş tepeli bir 1lıman iklim bitkisidir. Sonbaharda oluşan meyveleri önce yeşil sonra sarı ve kırmızı renk alır. Meyvesi yuvarlak, etli dış kabuk altında zarla bölünmüş odacıklarda bol miktarda bulunan taneli yapıya sahiptir. Narın anavatanı Güneybatı Asya'dan Hindistan, Pakistan ve İran'a kadar olan alandır. Daha sonra Akdeniz bölgelerinden Asya ve Çin'e kadar bir kültür bitkisi olarak da yetiştirilmiştir (Karadağ, 2007, s. 86). Nar, Türkiye'nin her bölgesinde görülmekle birlikte, genellikle Ege, Akdeniz ve Güneydoğu Anadolu bölgelerinde bolca yetişmektedir.

Narın meyve kabuklarında boyarmadde özelliği taşıyan ellag asidi bulundurmaktadır (Arlı, Kayabaşı, Şanlı ve Etikan, 2003, s. 35). Bitkisel boyacılık açısından narın meyve kabuklarından yararlanılarak hazırlanan boyarmadde ile genellikle mordanlı boyama yöntemi uygulanmaktadır. Genelde şapla mordanlanmış yünlerde kızıl sarı elde edilmekte; aynı yünlere saçıkıbrıs da ilave edildiğinde siyah renge ulaşılabilmektedir (Parlak, 2007, s. 127). Boyama işleminde kullanılan bu yardımcı maddeler mordan olarak isimlendirilir. Mordanlar, lifleri boyayı almaya hazırlamakta ve boyarmaddelerin liflere daha iyi tutunmasına yardımcı olmaktadır (Udale, 2014, s. 58).

Doğal boyamaların gelişimine paralel, ülkemizde mordan olarak kullanılan çeşitli maddeler bulunmaktadır. Mordanlar doğal ve kimyasal olarak gruplandırılmaktadır. Doğal mordanlara, meşe palamudu, sirke, turunç suyu, sütleğen sütü, meşe ağacının kökü, sığır idrarı, taş yosunları, kil, kireç, ekmek hamuru mayası ve odun külü gibi örnekler verilebilir. Kimyasal mordanlardan bazıları ise şap, göztaşı, saçıkıbrıs, potasyumbikromat, kremtartar ve sodyumsülfat vb.'dir (Başaran ve Sarıkaya, 2015, s. 453; Başaran ve Bakır, 2018, s. 105; Uğur, 1988, s. 11-12; Erdem İşmal ve Yıldırım, 2019, s. 6). 
Mordanların cinsine, türüne ve mordanlama yöntemine göre (ön, aynı anda veya art mordanlama) doğal boya ile çeşitli renkler, tonlar ve renk haslık değerleri elde edilebilmektedir. Aynı doğal boya ile sadece mordan türünü değiştirerek birbirinden farklı boyama sonuçları görülebilir (Erdem İşmal, 2019, s. 43). Bir boya maddesi ile yapılan boyama haslığı, boya miktarına, boyanan malzemeye ve boyamadan önce, boyama esnasında ve boyamadan sonra tekstil malzemesine uygulanan işlemlere bağlıdır (Türk Standartları Enstitüsü, 1999, s. 8). Aynı şekilde Erdem İşmal (2019, s. 43), doğal boya kaynağının cinsi, kurutma şekli, kullanılan kısmı, özütleme (ekstraksiyon) ş̧ekli ve boyama koşullarını (su/kimyasal çözgen kullanımı, nötr/asidik/bazik ortam (pH), sıcaklık, süre) elde edilecek sonuçları etkileyen başlıca etkenler olarak değerlendirmektedir.

Dolayısıyla haslık, sadece kullanılan boyanın özelliğine bağlı değildir, uygulanan boyama işlemlerinin de önemi büyüktür. Nar bitkisinin, kabuk, çiçek ve yapraklarından elde edilen boyarmadde ve doğal mordanlarla boyanan yün ve pamuk ipliklerinin renk özellikleri ve haslık düzeylerini konu alan bu çalışmada, işlem süreçleri ve koşulları da dikkatle ele alınmış ve uygun başlıklar altında açıklanmıştır.

\section{YÖNTEM}

Araştırmanın materyalini; nar (Punica Granatum L.) kabuğu, yaprağı ve bodur nar (süs nar) çiçeği boyarmaddeleri; labada kökü, kül suyu doğal mordanları ile yün ve pamuk ipliği oluşturmaktadır. Deneme modelinde yürütülen çalışmada boyama işlemleri, Giresun ili Tirebolu ilçesinde İl-Ca (Bitkisel Ürünler Ar-Ge Üretim) işletmesinde gerçekleştirilmiştir. Nar bitkisinin üç farklı kısmından elde edilen boyarmaddeler ile iki doğal mordan kullanılarak, mordansız ve birlikte mordanlama olmak üzere toplam 18 adet boyama yapılmıştır.

Hazırlanan reçetelerde uygulanan mordanlama yöntemi, kullanılan mordan, boyarmadde, iplik hammaddesi, iplik ağırlığı, boyama sıcaklığı ve boyama süresi çizelge halinde sunulmuştur. Yapılan çalışmalar sonucunda elde edilen renkler için subjektif renk değerlendirmesi, sürtünme ve yıkama haslık analizleri yapılmıştır. Renklerin adlandırılması için öğretim üyelerinden oluşan 10 kişilik uzman komisyon tarafindan subjektif değerlendirme yapılarak, tekstil cmyk pantone kodlarına göre renk isimleri tespit edilmiştir. Yıkama ve sürtünme haslık analizleri yapılmış, gri skala ile değerlendirilerek sonuçlar tablolaştırılmışıı.

Boyanan ipliklerin haslık testleri ve yorumlamaları Türk Standartlanı Enstitüsü tarafından hazırlanan yıkama haslık testi TS EN ISO 105-C06 (Tekstil- Renk Haslığı Deneyleri- Bölüm C06: Evsel Yıkamaya ve Ticari Müesseselerde Yıkamaya Karşı Renk Haslığı); sürtme haslık testi TS EN ISO 105-X12 (Tekstil- Renk Haslığı Deneyleri- Bölüm X12: Sürtmeye Karşı Renk Haslığı Tayini) standartlarına uygun olarak yapılmıştır. Solma ve akmanın değerlendirilmesinde; TS 423-2 EN 20105- A02 (TekstilRenk Haslığı Tayin Metodları- Bölüm A02 Solmanın Değerlendirilmesinde Gri Skalanın Kullanılması), TS 423-3 EN 20105- A03 (Tekstil- Renk Haslığı Tayini Metodları- Bölüm A03 Renk Akmasının Değerlendirilmesinde Gri Skalanın Kullanılması) standartları kullanılmıştır. Yıkama ve sürtme haslık testleri gri skalaya göre değerlendirilerek sonuçlar çizelge halinde hazırlanmıştır.

\section{BULGULAR VE YORUM}

\subsection{Boyarmaddenin Elde Edilmesi}

Araştırmada kullanılan tüm materyaller uygun şartlarda kurutularak hazırlanmıştır. Bitkinin belirtilen kısımlarından geleneksel yöntemle boyarmadde elde edilerek sıvı özütleri alınmıştır.

Tablo 1. Boyarmaddenin elde edilmesi

\begin{tabular}{lrrrr}
\hline Bitki kısımları & Bitki miktarı & Su miktarı & Kaynatma süresi & Demlenme süresi \\
\hline Nar kabuğu & 4gr. & $120 \mathrm{ml}$. & $2 \mathrm{saat}$ & $30 \mathrm{dk}$. \\
\hline Nar yaprağı & 4gr. & $120 \mathrm{ml}$. & $1-2 \mathrm{saat}$ & $30 \mathrm{dk}$. \\
\hline Nar çiçeği & 4gr. & $120 \mathrm{ml}$. & $1 \mathrm{saat}$ & $30 \mathrm{dk}$. \\
\hline
\end{tabular}

Nar kabukları, yaprak ve çiçekleri iplik ağırlığına göre 1:1 oranında alınarak 4 gr. tartılmış, "iplik ağırlığı x 30=120 ml." soğuk su ölçümleri yapılmıştır. Her biri belirtilen sürelerde kaynatılarak, 30-dakika soğumaya bırakılmıştır. Demlenme sonrasında boya flottesinden bitki posası süzülerek uzaklaştırılmış ve elde edilen sıvı boya özütü uygun ortama alınmıştır. 


\subsection{Mordanların Hazırlanması}

Mordanlar, hayvansal ve bitkisel liflerin boyanmasında boyarmaddenin elyaf cinsine göre bağlanması sonucunda, mordanlama yönteminin etkisine göre, farklı tonda renk çeşitleri elde edilerek, iyi bir renk haslığı sağlamak için kullanılmaktadır. Mordan niteliği olan doğal ve kimyasal mordanlar ile aynı boyarmaddeden farklı renkler elde edilmektedir (Eyüboğlu ve diğerleri, 1983, s. 32; Parlak, 1997, s.50).

Araştırmada kullanılan doğal mordan maddeleri şu şekilde hazırlanmıştır:

Yabani Labada Kökü: Labada bitkisinin kökleri parçalanarak hassas terazide tartılmıştır. İplik ağırlı̆̆ı kadar eklenen su ile 1 saat kaynatılmış ve demlemeye bırakılmıştır. Bu işlemlerden sonra labada kökü mordanı boyamada kullanılmak üzere hazır hale gelmiştir.

Kül Suyu: Yumuşak, beyaz ve temiz bir kül özelliği taşımasından dolayı, çalışmada doğal mordan olarak incir ağacının külü kullanılmıştır. Geleneksel kül suyu hazırlama baz alınarak, kül suyunun alkalik ortamından yararlanılmış, $95^{\circ} \mathrm{C}$ 'de su ilave edilerek çökmesi sağlanmıştır. Külün üzerinde kalan duru su alınarak kullanıma hazır hale getirilmiştir.

\subsection{Boyama Reçetesine Göre Çözelti Hazırlama ve Boyama İşlemi}

Nar kabuğu, yaprağı ve çiçeğinden elde edilen boyarmaddeler ile aynı reçete oranları kullanılmış ve her biriyle " 2 mordan, 2 boyama yöntemi, 2 hammadde" olmak üzere boyama yapılmıştır. Önce boyama reçeteleri hazırlanarak, kullanılacak malzemelerin ölçüm ve tartım işlemleri yapılmıştır. Nar kabuğu, yaprak ve çiçek kısımlarından elde edilen boyarmaddeler ile flotte oran1, 1/30 bitki boyarmaddesi boyanacak ipliğin ağırlığına göre 1:1 oranında alınmıştır. Numune ağırlığının 30 katı kadar su ve her bir mordandan, materyalin \% 50'si kadar labada kökü, su oranının \% 5'i kadar kül suyu kullanılmıştır.

Tablo 2. Nar kabuk, yaprak ve çiçek boyarmaddesi ile yün ve pamuk ipliği boyama reçetesi

\begin{tabular}{|c|c|c|c|c|}
\hline \multirow[t]{2}{*}{ Boyarmadde } & Cinsi & \multicolumn{3}{|c|}{ Nar kabuğu, nar yaprağı, nar çiçeği } \\
\hline & Miktar & 4 gr./lt & & \\
\hline \multirow[t]{2}{*}{ İplik } & Cinsi & Yün iplik, Pamuk iplik & & \\
\hline & Ağırlık & 4 gr. & & \\
\hline \multirow[t]{2}{*}{ Mordan } & Cinsi & Labada kökü & Kül suyu & \\
\hline & Oran/Miktar & $\% 50=2$ gr./lt & $\% 5=6$ gr./lt & \\
\hline \multirow[t]{4}{*}{ Boyama } & Yöntem & Mordansız, Birlikte mo & & \\
\hline & Sıcaklık & $90{ }^{\circ} \mathrm{C}$ & & \\
\hline & Süre & $60 \mathrm{dk}$ & & \\
\hline & Su oranı & $120 \mathrm{ml}$. & & \\
\hline \multirow[t]{4}{*}{ Ph değeri } & & Nar kabuğu & Nar yaprağ & Nar çiçeği \\
\hline & Mordansız & 3 & 4 & 2,34 \\
\hline & Labada kökü & 4 & 4 & 2,70 \\
\hline & Kül suyu & 9 & 6,5 & 9,20 \\
\hline
\end{tabular}

Boyamada, işlem görmemiş çile halindeki yün ve pamuk ipliklerinden yararlanılmış ve tartım sonucunda iplik numuneleri boyamaya hazır hale getirilmiştir.
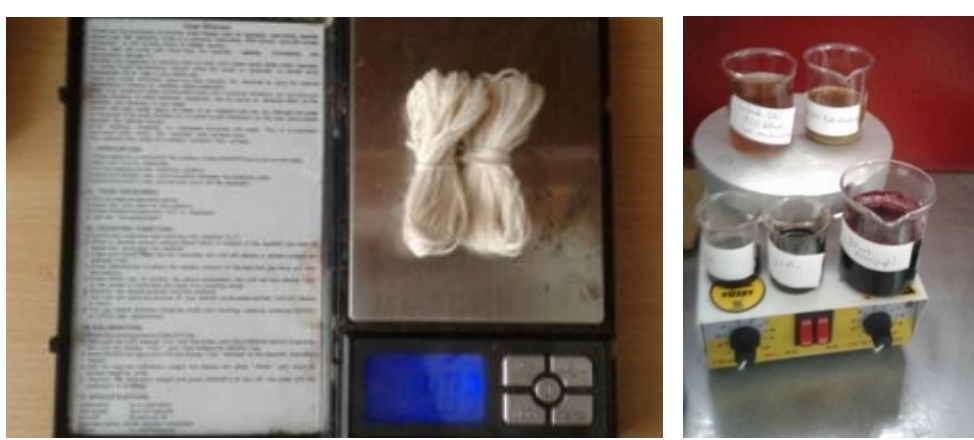

Şekil 1. Hazırlanan iplik ve çözeltiler (Aydın, 2018) 
Nar kabuğu, yaprağı ve çiçeği ile elde edilen boyarmaddelerle; boyarmadde miktarları, mordanlama yöntemleri, mordan ve su oranları aynı kalmak koşuluyla, beher kabında her bitkiden sıra ile üçer adet çözelti hazırlanmıştır. Boya banyosu için hazırlanan çözeltilerin, beherde $\mathrm{pH}$ değer ölçümü yapılmış ve değer tespitinde $\mathrm{pH}$ kağıdı kullanılmıştır. Nar çiçeği çözeltisinin $\mathrm{pH}$ ölçümü ise $\mathrm{pHmatik}$ ile yapılmıştır. Boyama, mordansız ve birlikte mordanlama yöntemi ile gerçekleştirilerek şu şekilde uygulanmıştır:

Mordansız boyama işlemi: Önceden nemlendirilen iplikler direkt olarak boya banyosuna alınmıştır. Yün ve pamuk ipliği ile 6 adet mordansız boyama uygulanmıştır.

Birlikte mordanlama ișlemi: Boyama reçetesine göre hazırlanan mordan maddeleri boyarmadde çözeltisi içine karıştırılarak eritilmiştir. Çözelti ile nemlendirilmiş iplikler, numara sırasına göre test tüplerine yerleştirilmiş ve 12 adet iplik numunesi birlikte mordanlama işlemine tabi tutulmuştur.
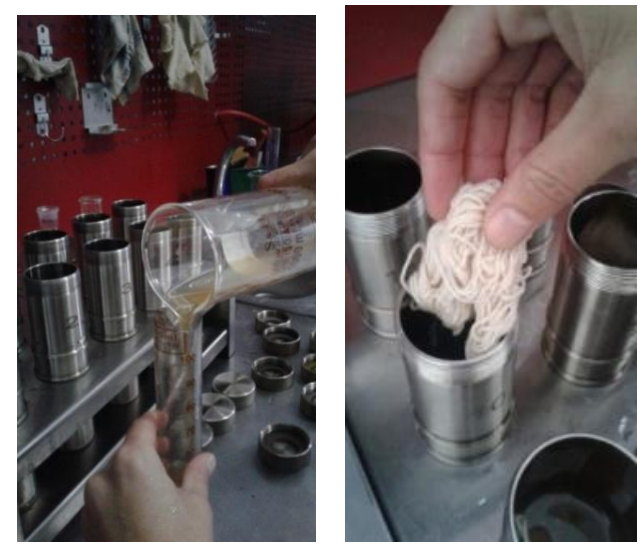

Şekil 2. Çözelti ve ipliklerin test tüplerine aktarımı (Aydın, 2018)

Boyama işlemi: Boya tüpleri, boya makinesinin yuvalarına yerleştirilmiştir. Boya makinesi, belirlenen boyama grafiğine göre 60 dakika, $90^{\circ} \mathrm{C}$ sıcaklıkta ayarlanarak çalıştırılmış ve boyama işlemi gerçekleştirilmiştir. Boya tüpleri, makine yuvasından çıkartılarak boyanan iplikler test tüplerinden alınmış, üzerindeki fazla boya atılana kadar soğuk su ile yıkama yapıldıktan sonra kurumaya bırakılmıştır.

\subsection{Boyamada Elde Edilen Renkler}

Tablo 3. Nar bitkisinin kabuk, yaprak ve çiçek kısımlarından elde edilen renkler

\begin{tabular}{|c|c|c|c|}
\hline \multirow{3}{*}{$\begin{array}{l}\text { Mordan } \\
\text { Maddeleri }\end{array}$} & \multicolumn{3}{|c|}{$\underline{\text { Nar Kabuğu }}$} \\
\hline & \multicolumn{3}{|c|}{$\underline{\text { Pantone Değerleri ve Boyanmıș İplikler }}$} \\
\hline & & & Pamuk \\
\hline \multirow{2}{*}{ Mordansiz } & Plantation TC & Camel TC & \\
\hline & PANTONE 18-0832 & PANTONE 17-1224 & \\
\hline \multirow[t]{2}{*}{ Labada kökü } & Light Olive Green TC & Pale Khaki TC & \\
\hline & PANTONE 16-0847 & PANTONE 15-1216 & \\
\hline \multirow[t]{2}{*}{ Kül suyu } & Reed Yellow TC & Ecru TC & \\
\hline & PANTONE 13-0915 & PANTONE 11-0809 & \\
\hline Mordan & & & \\
\hline \multirow[t]{2}{*}{ Maddeleri } & & anmıș İplikler & \\
\hline & & & Pamuk \\
\hline \multirow[t]{2}{*}{ Mordansiz } & Light Olive Green TC & Wood Ash TC & \\
\hline & PANTONE 16-0847 & PANTONE 14-1108 & \\
\hline \multirow[t]{2}{*}{ Labada kökü } & Golden Olive TC & Shadow Green TC & \\
\hline & PANTONE 16-0639 & PANTONE 14-0627 & \\
\hline \multirow[t]{2}{*}{ Kül suyu } & Rafia TC & Ecru TC & \\
\hline & PANTONE 13-0725 & PANTONE 11-0809 & \\
\hline Mordan & \\
\hline \multirow[t]{2}{*}{ Maddeleri } & \multicolumn{2}{|c|}{ Pantone Değerleri ve Boyanmıș İplikler } & \\
\hline & & & Pamuk \\
\hline Mordansiz & $\begin{array}{r}\text { Russet Brown TC } \\
\text { PANTONE 19-1338 }\end{array}$ & $\begin{array}{r}\text { Taupe Gray TC } \\
\text { PANTONE } 17-0808\end{array}$ & \\
\hline
\end{tabular}




\begin{tabular}{l|r|r}
\hline Labada kökü & Cinnabar TC & Cuban Sand TC \\
& PANTONE 18-1540 & PANTONE 15-1314 \\
\hline Kül suyu & Cornstalk TC & Ivory Cream TC \\
& PANTONE 16-1315 & PANTONE 13-1011 \\
\hline
\end{tabular}

Nar bitkisinin üç farklı kısmı ile boyanan yün ve pamuk ipliklerinde aynı mordan maddesi ile birbirinden farklı tonlarda renkler elde edilmiştir. Renk değişimlerinde, boyarmadde, mordan, boyama yöntemleri ve uygulanan iplik türü önemli rol oynamaktadır.

Renk farklılıklarının, bitki kısımları, boya bitkisinin toplama ve kurutma zamanı, boyarmaddenin bekleme ve boyama süresi, iplik cinsleri, boyama yöntemleri, pH değeri, doğal mordanların özellikleri ve mordan konsantrasyonuna bağlı olarak, uygulanan elyafa göre oluşturduğu bağlanmanın etkisinden kaynaklandığı düşünülmektedir.

\subsection{Nar Kabuğu ile Boyanmış İpliklerin Haslık Değerleri}

Tablo 4. Nar kabuğu ile boyanan yün ve pamuk ipliği numunelerinin yıkama ve sürtünme haslık sonuçları

\begin{tabular}{|c|c|c|c|c|c|c|c|c|}
\hline \multirow{4}{*}{$\begin{array}{l}\text { Mordansız ve } \\
\text { Birlikte } \\
\text { Mordanlama }\end{array}$} & \multicolumn{8}{|c|}{ Nar Kabuğu } \\
\hline & \multicolumn{4}{|c|}{ Y1kama Haslığ1 } & \multicolumn{4}{|c|}{ Sürtünme Haslığ1 } \\
\hline & \multicolumn{2}{|c|}{ Yün } & \multicolumn{2}{|c|}{ Pamuk } & \multicolumn{2}{|c|}{ Yün } & \multicolumn{2}{|c|}{ Pamuk } \\
\hline & Akma & Solma & Akma & Solma & Kuru & Islak & Kuru & Islak \\
\hline Mordansız & 1 & $4 / 5$ & 2 & $4 / 5$ & 5 & 4 & 5 & 4 \\
\hline Labada kökü & $1 / 2$ & 5 & 3 & $4 / 5$ & 2 & $3 / 4$ & 2 & 2 \\
\hline Kül suyu & $4 / 5$ & $4 / 5$ & 4 & 4 & $4 / 5$ & $4 / 5$ & $4 / 5$ & 5 \\
\hline
\end{tabular}

Mordansız boyanan yün ve pamuk ipliklerinin haslık değerlendirme sonuçlarına göre, yıkama haslığ1 akma değerinin yün iplikte az, pamuk iplikte orta değerde olduğu; sürtünme haslığında ise oldukça iyi değerde olduğu görülmüştür.

Labada kökü mordanı birlikte mordanlama yöntemiyle boyanan yün ve pamuk ipliklerinin haslık değerlendirme sonuçları, yıkama haslığı akma değerleri yün iplikte az, solma değerleri iyi düzeydedir. Sürtünme haslık sonuçlarında ise her iki iplik cinsinde kuru değerlerin orta, 1slak değerlerin ortalama iyi olduğu görülmektedir.

Kül suyu mordanı ve birlikte mordanlama yöntemiyle boyanan yün ve pamuk ipliklerinin haslık değerlendirme sonuçları tüm boyamalarda oldukça iyi değerdedir.

Genel olarak yapılan haslık sonuçları değerlendirildiğinde; boyamada en iyi haslık değerlerinin birlikte mordanlama ile kül suyu mordanından elde edilen sonuçlar olduğu tespit edilmiştir.

\subsection{Nar Yaprağı ile Boyanmış İpliklerin Haslık Değerleri}

Tablo 5. Nar yaprağı ile boyanan yün ve pamuk ipliği numunelerinin yıkama ve sürtünme haslık sonuçları

\begin{tabular}{|c|c|c|c|c|c|c|c|c|}
\hline \multirow{4}{*}{$\begin{array}{l}\text { Mordansiz ve } \\
\text { Birlikte } \\
\text { Mordanlama }\end{array}$} & \multicolumn{8}{|c|}{ Nar Yaprağı } \\
\hline & \multicolumn{4}{|c|}{ Yıkama Haslığ } & \multicolumn{4}{|c|}{ Sürtünme Haslığ1 } \\
\hline & \multicolumn{2}{|c|}{ Yün } & \multicolumn{2}{|c|}{ Pamuk } & \multicolumn{2}{|c|}{ Yün } & \multicolumn{2}{|c|}{ Pamuk } \\
\hline & Akma & Solma & Akma & Solma & Kuru & Islak & Kuru & Islak \\
\hline Mordansız & $1 / 2$ & 5 & 2 & $3 / 4$ & 4 & $2 / 3$ & 5 & 4 \\
\hline Labada kökü & 2 & 5 & 5 & $2 / 3$ & 3 & 3 & 5 & 4 \\
\hline Kül suyu & 3 & $4 / 5$ & 4 & 4 & 4 & $4 / 5$ & 5 & 5 \\
\hline
\end{tabular}

Mordansız boyanan yün ve pamuk ipliklerinin yıkama haslıklarında, akma değeri yün ipliğinde az, pamuk iplikte orta değerdedir. Solma ve sürtünme haslıklarında ise iyi değerde oldukları görülmüştür.

Labada kökü mordanı ve birlikte mordanlama yöntemiyle boyanan yün ve pamuk ipliklerinin haslık değerlendirmelerinde, yıkama haslığının değişkenlik gösterdiği; sürtünme haslık sonuçlarının ise yün iplikte eşit değerde iyi, pamuk ipliğinde oldukça iyi düzeyde olduğu görülmektedir. 
Kül suyu mordanı, birlikte mordanlama yöntemiyle boyanan yün ve pamuk ipliklerinin haslık değerlendirme sonuçlarının tüm boyamalarda oldukça iyi değerde olduğu görülmüştür.

Genel olarak yapılan haslık sonuçları değerlendirildiğinde, boyamada en iyi haslık değerlerinin birlikte mordanlama ile kül suyu mordanından elde edilen renkler olduğu tespit edilmiştir.

\subsection{Nar Çiçeği ile Boyanmış İpliklerin Haslık Değerleri}

Tablo 6. Nar çiçeği ile boyanan yün ve pamuk ipliği numunelerinin yıkama ve sürtünme haslık sonuçları

\begin{tabular}{|c|c|c|c|c|c|c|c|c|}
\hline \multirow{4}{*}{$\begin{array}{l}\text { Mordansiz ve } \\
\text { Birlikte } \\
\text { Mordanlama }\end{array}$} & \multicolumn{8}{|c|}{ Nar Çiçeği } \\
\hline & \multicolumn{4}{|c|}{ Y1kama Haslığ1 } & \multicolumn{4}{|c|}{ Sürtünme Haslığı } \\
\hline & \multicolumn{2}{|c|}{ Yün } & \multicolumn{2}{|c|}{ Pamuk } & \multicolumn{2}{|c|}{ Yün } & \multicolumn{2}{|c|}{ Pamuk } \\
\hline & Akma & Solma & Akma & Solma & Kuru & Islak & Kuru & Islak \\
\hline Mordansiz & 5 & 1 & 2 & 1 & 4 & $4 / 5$ & 5 & $4 / 5$ \\
\hline Labada kökü & 1 & 5 & 3 & $2 / 3$ & 3 & $4 / 5$ & 5 & 5 \\
\hline Kül suyu & $3 / 4$ & 5 & 5 & 5 & $2 / 3$ & 3 & 5 & 5 \\
\hline
\end{tabular}

Mordansız boyanan yün ve pamuk ipliklerinin haslık değerlendirme sonuçlarına gore, yıkama haslığının yün iplik boyamalarında renk değişiminden dolayı akma ve solma değerlerinde değişkenlik gösterdiği, sürtünme haslığında ise oldukça iyi değerde olduğu görülmüştür.

Labada kökü mordanı ve birlikte mordanlama yöntemiyle boyanan yün ve pamuk iplikleri haslık değerlendirme sonuçlarında, yine yün ipliklerde akma ve solma değerlerinin değişkenlik gösterdiği tespit edilmiştir. Pamuk ipliğinde ortalama iyi değerde, sürtünme haslık sonuçlarında ise oldukça iyi değerdedir.

Kül suyu mordanı, birlikte mordanlama yöntemiyle boyanan yün ve pamuk ipliklerinin haslık değerlendirme sonuçlarına göre, pamuk ipliklerindeki haslıkların çok iyi değerde, diğer boyamalardaki haslıkların oldukça iyi değerde olduğu görülmüş̧ür.

Genel olarak boyamada en iyi haslık değerlerinin, birlikte mordanlama ile kül suyu mordanından elde edilen renkler olduğu tespit edilmiştir.

\section{SONUÇ ve ÖNERILLER}

Sonuç olarak, doğal mordanlar kullanılarak, yün ve pamuk iplikleri ile yapılan boyamalarda nar kabuğu ve nar yaprağı ile yakın renk tonları elde edilirken, nar çiçeği ile ulaşılan renklerin farklı olduğu sonucuna ulaşılmıştır.

Subjektif değerlendirmelerde "tekstil pantone kodları ve CMYK karş1lıkları"ndan (URL 1) yararlanılmıştır. Deneysel çalışmada genellikle açık ve orta tonlarda renkler elde edilmiştir. Nar kabuğu renklerinin yün ipliklerde açık ve parlak tonlarda zeytin yeşili ve saman sarısı tonlarında olduğu; pamuk ipliklerinde ise deve tüyü, açık haki, ekru gibi mat tonların meydana geldiği görülmüştür. Nar yaprağı renklerinin yün ipliklerde açık ve orta tonlarda zeytin yeşili olduğu; pamuk ipliklerinde ise mat tonlarda kereste ve ekru renklerin elde edildiği görülmüştür. Nar çiçeği renkleri yün ipliklerinde daha koyu ve parlak tonlarda kızıl ve açı kahve tonlarındadır. Pamuk ipliklerinde ise bu renkler daha mat şekilde boz kahverengi ve tonlarında meydana gelmiştir.

Genel değerlendirmeler sonucunda; nar bitkisinin çeşitli kısımları ile işlem gören kül suyu ve labada kökü mordanlarının, yün ve pamuk ipliklerinde farklı renk tonları ile sonuçlandığı gibi, farklı yıkama ve sürtünme haslık değerlerine ulaştığı belirlenmiştir. $\mathrm{Bu}$ çalışmada elde edilen haslık değerleri doğrultusunda, doğal boyamacılıkta kimyasal mordanların mümkün olduğunca terk edilerek doğal mordan maddelerinin tercih edilebileceği; organik tarım ve organik yaşam gibi terim ve uygulamaların gittikçe değer kazandığı günümüzde bu tür sonuçların umut verici olduğu düşünülmektedir.

Ayrıca doğal mordan çeşitleri, mordan konsantrasyonları değiştirilerek, boyama sıcaklığı, pH değerleri, süre ve yöntemleri ile ilgili farklı reçeteler hazırlanarak yeni deneysel araştırmalar yapılabilir. Böylece bitkisel atıkların geri dönüşüm olarak değerlendirilmesi açısından farklı bitkiler ve mordanlar ile renk ve haslık değerlerine ulaşılarak tekstil sektörüne katkı sağlanabilecektir. 


\section{KAYNAKÇA}

Alkan, R., Torgan, E. ve Karadağ, R. (2017). The investigation of antifungal activity and durability of natural silk fabrics dyed with madder and gallnut. Journal of Natural Fibers, 14(6), 769-780. DOI: 10.1080/15440478.2017.1279101.

Arlı, M., Kayabaşı, N., Şanlı, H. S. ve Etikan, S. (2003). Türkiye'de bitkisel boyacıllkta kullanılan bazı bitkilerden elde edilen renklerin colorımeter ile tayini üzerine bir araştırma. Ankara: Ankara Üniversitesi Ev Ekonomisi Mezunları Derneği Yayınları.

Başaran, F. N. ve Bakır, G. (2018). Yeşil çay ile doğal boyama çalışmaları ve haslık düzeylerinin belirlenmesi. İstanbul: ICUHTA, I. Uluslararası sanatta yüksek teknoloji kullanımı kongresi, İstanbul Gelişim Üniversitesi Yayınları.

Başaran, F. N. ve Sarıkaya, H. (2015). Investigation of nutgall and some natural dyes with mordants cotton dyeing and fastness level in the context of the ecological textile production. IjasosInternational E-Journal of Advances in Social Sciences, 1(3), 452-459.

Durul, Y. (1985). Anadolu kilimlerinden örnekler. İstanbul: Ak Yayınları.

Erdem İşmal, Ö. (2019). Doğal boya uygulamalarının değişen yüzü ve yenilikçi yaklaşımlar. YEDİ: Sanat, Tasartm ve Bilim Dergisi, (22), 41- 58.

Erdem İşmal, Ö. ve Yıldırım, L. (2019). An overview of faba bean: utilisation of husks in natural dyeing. International Journal of Clothing Science and Technology, 31(6).

Etikan, S. ve Ölmez, F. N. (2014). Fethiye'de bitkisel boyacılık geleneği ve günümüzdeki durumu. Kalemişi Türk Sanatları Dergisi, 2(4), 54-71.

Eyüboğlu, Ü., Okaygün, I. ve Yaraş, F. (1983). Doğal boyalarla yün boyama uygulamalı ve geleneksel yöntemler. İstanbul: Ofset Yapımevi.

Gönüz, A., Aksoy, A. ve Karabacak, E. (2006). Çanakkale ve çevresinde doğal yayılış gösteren bazı potansiyel boya bitkileri. Anadolu Ege Tarımsal Araştırma Enstitüsü Dergisi, 16(1), 54-71.

Harmancioğlu, M. (1955). Türkiye'de bulunan önemli bitki boylarından elde olunan renklerin çeşitli müessirlere karşı yün üzerinde haslık dereceleri. Ankara: Ankara Üniversitesi Ziraat Fakültesi Yayınları.

Karadağ, R. (2007). Doğal boyamacılık. Ankara: DÖSiM.

Öztürk, İ. (1999). Doğal bitkisel boyalarla yün boyama. 1. Baskı. İzmir: Dokuz Eylül Yayınları.

Parlak, T. (2007). Çoruh vadisinde bitkisel boya potansiyeli. Ankara: Atatürk Üniversitesi GSF. Yayını.

Soysaldı, A. (2000). Doğal boyacılık ve metodoloji. (Türk halk kültürü araştırmaları 1998), Ankara: Kültür Bakanlığı Halk Kültürlerini Araştırma ve Geliştirme Genel Müdürlüğü Yayınları.

Şanlı, H. S. ve Arlı, M. (2007). Bazı boya bitkileriyle ipekli tekstil ürünlerinin boyanması ve elde edilen renklerin belirlenmesi. Gazi Üniversitesi Endüstriyel Sanatlar Eğitim Fakültesi Dergisi, (21), 5578.

T.C. Sanayi ve Ticaret Bakanlı̆̆ı (1991). Bitkilerden elde edilen boyalarla yün lifinin boyanması. Ankara: Sanayi ve Ticaret Bakanlığı, Küçük Sanatlar ve Sanayi Bölgeleri ve Siteleri Genel Müdürlüğü.

Türk Standartları Enstitüsü. (1999). TS 423-1 EN ISO 105-A01 Tekstil- renk haslĭğ deneyleri- bölüm A01- deneylerle ilgili genel prensipler. Ankara: Türk Standartlar1 Enstitüsü.

Udale, J. (2014). Moda tasarımında tekstil ve moda. (çev. Hayriye Güngör). 1. Basım. İstanbul: Literatür Yayınları.

Uğur, G. (1988). Türk halılarında doğal renkler ve boyalar. Ankara: Türkiye İş Bankası Kültür Yayınları. 
URL 1: 19 Eylül 2019 tarihinde http://www.tolgakadakal.com/Tekstil-Tasarim-Renk\%C4\%B0simlerinin-Pantone-ve-CMYK-Karsiliklari/tr-TR/Article/1055/6 adresinden erişildi. 